\title{
Effect of Zinc Oxide Nanoparticles on Barrier and Mechanical Properties of EVOH Nanocomposite film Incorporating with Plasticizer
}

\author{
Kambiz Sadeghi*, Mohammad Shahedi \\ Department of Food Science and Technology, Isfahan University of Technology, Isfahan, Iran \\ *Corresponding author: kambiz_sadeghi@ymail.com
}

\begin{abstract}
In this study, ethylene vinyl alcohol copolymer (EVOH) nanocomposite was prepared by adding nano zinc oxide (nano- $\mathrm{ZnO}$ ) as a filling agent and glycerol as a plasticizer. In the solution mixing method, usually a plasticizer is used to prevent the film from becoming brittle. However, adding a plasticizer also has adverse effects on the film. Examples of such effects include; decreased barrier properties (water vapor permeability and oxygen permeability) and reduced mechanical properties (tensile strength (TS)). The goal of this study was, to reduce the adverse effects of the plasticizer on film's matrix by adding nanoparticles. Three concentrations $(0 \%, 1 \%$, and $2 \%)$ of Nano-ZnO were used in order to find the optimum concentration of glycerol $(30 \%, 40 \%$, and $50 \%)$ with the least significant adverse effect. Incorporating glycerol reduced the barrier and the tensile strength properties in matrix films, while, adding nano- $\mathrm{ZnO}$ improved barrier, tensile strength properties and reduced adverse effects of the glycerol. FE-SEM image analysis was used to confirm the adverse effects of glycerol on matrix film.
\end{abstract}

Keywords: barrier properties, EVOH, food packaging, Nano-ZnO, plasticizer

Cite This Article: Kambiz Sadeghi, and Mohammad Shahedi, "Effect of Zinc Oxide Nanoparticles on Barrier and Mechanical Properties of EVOH Nanocomposite film Incorporating with Plasticizer." Journal of Food and Nutrition Research, vol. 4, no. 11 (2016): 709-712. doi: 10.12691/jfnr-4-11-2.

\section{Introduction}

Today in the food industry, biopolymers and biodegradable polymers have become attractive packaging materials as the amount of oil based polymer waste increases. They are also safer for the human body and more sustainable. Ethylene vinyl alcohol (EVOH) copolymer is a widely used packaging material in food industry, due to its good oxygen barrier and aroma permeability properties. Its low permeability is a result of the ethylene present in the polymer [1]. Packaging materials with low permeability to gases and water vapor improve shelf life. EVOH polymer is transparent, biodegradable, environmentally friendly and safe for the human body [2]. These factors make EVOH useful as a food packaging material. According to Yeo et al., (2001) adding EVOH to polypropylene reduced its oxygen permeability. Additionally, reference [4] found that EVOH was a good material for the oxygen barrier properties needed for shelf stable foods.

Zinc oxide $(\mathrm{ZnO})$ nanoparticles are the most widely used nanoparticles in the food industry because it is more effective than its counterparts in the following areas: costeffectiveness, white appearance, and UV filtering properties [5]. In addition, nano zinc oxide showed antimicrobial properties in active food packaging [6]. Plasticizers are used to prevent the laminate film from becoming brittle; however, they also affect the permeability and mechanical properties of the film. The barrier property improvements can be attributed to effective dispersion nanoparticles in the film matrix [1].

Traditional materials used in the food packaging industry for their oxygen barrier properties, such as flexible aluminum foil, have been found to effect human health adversely [4]. Polymer nanocomposites consist of a polymer or copolymer containing nanoparticles, nanofillers or particles, which are nano-scale in one dimension, dispersed in the polymer's matrix [7]. Due to the dispersion of nanoparticles in the polymer matrix, the polymer is prepared by different physico-chemical and mechanical properties [2]. Substitutes for traditional packaging materials can be created by modifying polymers with nanotechnology.

Plasticizers, which are added to prevent brittleness in laminate films, cause adverse effects on a film's viability as a food packaging material. The main objective of this study was to produce a nanocomposite, which contained zinc oxide nanoparticles, in order to overcome these effects and create a better food packaging material than could be created by traditional methods.

\section{Materials and Methods}

\subsection{Materials}

The ethylene vinyl alcohol (ethylene 32mol \%) used in this work was purchased from Sigma-Aldrich. Nano Sany Corporation (Mashhad/Iran) provided the $\mathrm{ZnO}$ nanoparticles used in this study. Isopropanol and acetic acid were used 
as the solvents for $\mathrm{EVOH}$ and $\mathrm{ZnO}$ nanoparticles. They were obtained from Merck Company. The plasticizer, glycerol, was purchased from Sepahan Teb Company (Isfahan/Iran). The compounds used in study were kept under room temperature and normal light.

\subsection{Film Preparation}

To prepare the film, EVOH was dispersed in a mixture of $4 \%(\mathrm{w} / \mathrm{v})$ isopropanol/water (70/30 (v/v)) and stirred at $25^{\circ} \mathrm{C}$ for 60 minutes [8]. Nano-ZnO was dispersed in $1 \%$ (v/v) acetic acid and vortexed at $25^{\circ} \mathrm{C}$ for 5 minutes; then, it was exposed to an ultrasonic wave for 15 minutes. To prevent damage to the nanoparticles due ultrasonic wave, a small amount of glycerol was added to the nano-ZnO solution. After the glycerol was added as a plasticizer, the solution was stirred for 30 minutes [8]. Then the solution of film was homogenized for 2 minutes, followed by the ultrasonic for 20 minutes.

\subsection{Mechanical Properties}

Mechanical analysis was performed using an Instron texture analyzer according to ASTM D882. The percentage of elongation at breakage $\left(\varepsilon_{\mathrm{b}}\right)$ and tensile strength (TS) were measured at $50 \%$ relative humidity and $25^{\circ} \mathrm{C}$ for a week before examination. The film dimension and speed was $2.5 \times 10 \mathrm{~cm}$ and $50 \mathrm{~mm} \mathrm{mn}^{-1}$, respectively. The mechanical properties were measured in three replicates for individual sample [9].

\subsection{Water Vapor Permeability (WVP)}

WVP (g m/m $/ \mathrm{m}^{2} \mathrm{~s} \mathrm{~Pa}$ ) for nanocomposite films was performed according to ASTM E96-95.

$$
(\mathrm{WVP})=\frac{\mathrm{S} \times \mathrm{L}}{\mathrm{A} \Delta \mathrm{P}}
$$

Where, WVP denotes the measured water vapor permeability ( $\mathrm{g} \mathrm{m} / \mathrm{m}^{2} \mathrm{~s} \mathrm{~Pa}$ ), $\mathrm{S}$ is slope of line weight variation cup. A is the area of film $\left(\mathrm{m}^{2}\right)$, $\mathrm{L}$ is average thickness $(\mathrm{m})$ and $\Delta \mathrm{P}$ is the partial pressure difference on both sides of the film (Pa) [10]. The cups were placed in at $25^{\circ} \mathrm{C}$ and relative humidity $50-100 \%$. The cups were weighed for a period of 24 hours [2].

\subsection{Oxygen Permeability (OP)}

The OP test was performed as per ASTM D1434. According to this standard, changes in the height and volume of water were measured using a manometer made of silicon hose, which was installed on one side of the output module

$$
\mathrm{v}\left(\pi \mathrm{r}^{2}\right) \mathrm{L} /\left(\pi \mathrm{R}_{2}\right)\left(\mathrm{P}_{1}-0\right)=(\mathrm{dh} / \mathrm{dt})\left(\pi \mathrm{r}^{2}\right) \mathrm{L} /\left(\pi \mathrm{R}^{2}\right) \mathrm{P}(2)
$$

Where $\mathrm{P}$ is the measured permeability of film matrix ( $\mathrm{ml} . \mu \mathrm{m} / \mathrm{m}^{2}$.day.Kpa), $\mathrm{R}$ is the effective diameter of the surface membrane $(\mathrm{m}), \mathrm{r}$ is the diameter of water tube, $\mathrm{P}$ is the pressure above membrane and $\mathrm{dh} / \mathrm{dt}$ is the (the slop of diagram height of water to time) water velocity [11].

\subsection{Microscopy Characterization}

Field Emission Scanning Electron Microscopy (FESEM) was used to assess morphology of the cross- sections of the nanocomposite film. Small pieces $(0.5 \times$ $0.5 \mathrm{~cm}$ ) of the film were coated with a thin layer of nanogold under vacuum in a sputter coating unit and immediately evaluated by SEM [12].

\section{Results and Discussion}

\subsection{Mechanical Properties}

Table 1 shows the mechanical properties of the EVOH film. According to the table, increasing the glycerol concentration reduced the tensile strength of film. This can be attributed to the internal lubrication of the film's matrix that decreased internal friction, and consequently, decreased the tensile strengthen of film. However, adding nano-ZnO increased the tensile strength, which created a crystal structure and increased the internal friction of the film's matrix [13]. This crystal structure was probably the result of the cross link between the polymer and nanoparticles in the film's matrix. According to Table 1, although the maximum tensile strength measured when adding nanoparticles occurred at 30\% glycerol concentration, there are the glycerol percentage increased, the effect of the nano- $\mathrm{ZnO}$ on the film's matrix increased.

In addition, increasing the nano-ZnO concentration diminished the adverse effects of the glycerol more significantly. For example in pure film (0\%), the reduction rate of tensile strength as result of adding glycerol, was found to be $16.5 \mathrm{MPa}$ (varying 30\% to 50\%); however, the result for $2 \%$ nano-ZnO was $10.5 \mathrm{MPa}$. This result can be attributed to the nanoparticles' ability to create crosslinks in the delaminated structure caused by the addition of the glycerol.

Table 1. Mechanical Properties of the EVOH Film

\begin{tabular}{cccc}
\hline & \multicolumn{3}{c}{ Tensile Strength (MPa) } \\
\cline { 2 - 4 } Glycerol(\%) & $\mathbf{3 0 \%}$ & $\mathbf{4 0 \%}$ & $\mathbf{5 0 \%}$ \\
\hline ZnO(\%) & & $58.4 \pm 2.1$ & $53.3 \pm 4.7$ \\
0 & $69.7 \pm 2.8$ & $66.5 \pm 3.7$ & $59.3 \pm 2.3$ \\
1 & $73.31 \pm 5$ & $72.1 \pm 3.2$ & $69.1 \pm 2.7$ \\
2 & $79.6 \pm 3.9$ & $\mathbf{4 0 \%}$ \\
\hline & & Elongation at Breakage (\%) \\
Glycerol(\%) & $\mathbf{3 0 \%}$ & $218 \pm 54$ & $\mathbf{5 0 \%}$ \\
\hline ZnO(\%) & \multicolumn{3}{c}{$227 \pm 56$} \\
0 & $212 \pm 87$ & $247 \pm 64$ & $257 \pm 49$ \\
1 & $225.3 \pm 68$ & $235.6 \pm 56$ & $247.3 \pm 48$ \\
\hline
\end{tabular}

According to Table 1, as the glycerol concentration increased, the percentage of elongation at breakage $\left(\varepsilon_{\mathrm{b}}\right)$ increased. According to reference [13] adding a plasticizer breaks down the polymer-polymer 3D structure of the film's matrix, which creates a new delaminated structure in the film's matrix; the new film has elongation properties. Table 1 shows that adding a $1 \%$ concentration of nanoparticles increased $\varepsilon_{\mathrm{b}}$ while adding a $2 \%$ concentration of nanoparticles decreased $\varepsilon_{\mathrm{b}}$. The reduction from $1 \%$ to $2 \%$ nanoparticle concentration is likely attributed to an increase in the crystalline structure and internal friction of the film's matrix.

\subsection{Water Vapor Permeability (WVP)}

Figure 1 shows the WVP of the EVOH film. According to Figure 1, adding nanoparticles caused the reduction in 
WVP. In general, adding nanoparticles to a polymer causes a decrease in its WVP because nanoparticles increase the path the water vapor must travel in order to diffuse [14].

Figure 1 shows that the increase in WVP was a result of adding glycerol, but as the concentration of nano-ZnO increased, the effect of the glycerol was reduced. To illustrate, the reduction rate for WVP was 6.7, 5.17, and $2.32 \mathrm{~g}-\mathrm{m} / \mathrm{m}^{2}$.s.Pa at $0 \%$ (pure film), $1 \%$, and $2 \%$ nano$\mathrm{ZnO}$ concentration, respectively. It is worth noting that nanoparticles reduced the adverse effect of glycerol on the film's matrix, and the reduction rate for the water vapor permeability was decreased. Presumably, this effect was caused by the dispersed nano-ZnO acting as a nano-filler.

According to Figure 1, the addition of glycerol increased the WVP. In general, adding a plasticizer to a polymer creates non-uniform structure and unconventional cohesion in the film's matrix. ${ }^{-11}$ to $54.1 \times 10^{-11} \mathrm{~g} / \mathrm{m}$.s.Pa at $25^{\circ} \mathrm{C}$ and 50-100 RH.

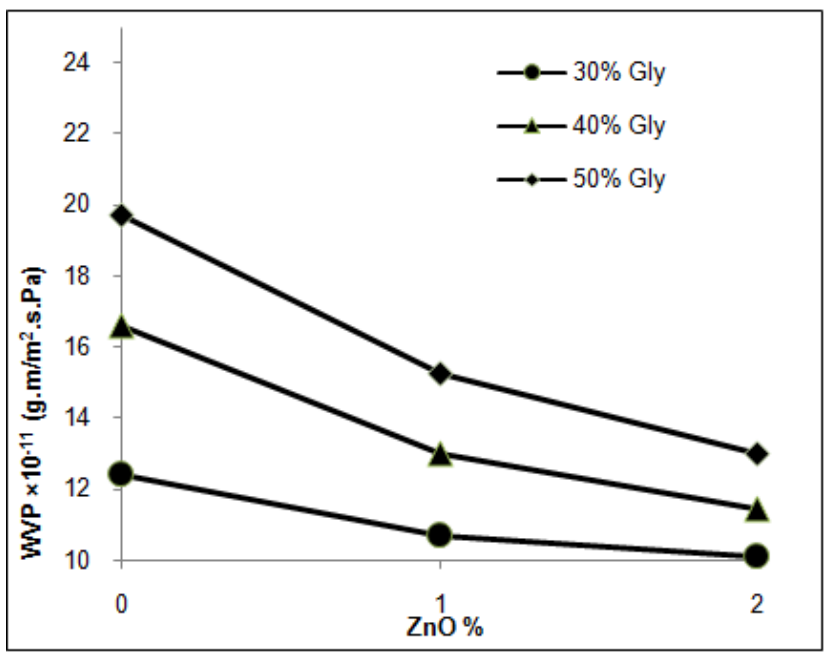

Figure 1. WVP of the EVOH Film(Gly = Glycerol $)$

In addition, it causes the film to develop pores for water vapor to pass through (López et al., 2010). According to reference [16], adding nanoclay to chitosan caused a 0.7 (g/m².day.mmHgmm) reduction in WVP. Similarly, adding $2 \%$ concentration of nano-ZnO decreased the water vapor permeability by approximately $2.32 \times 10^{-11} \mathrm{~g}$ $\mathrm{m} / \mathrm{m}^{2}$.s.Pa at $30 \%$ glycerol.

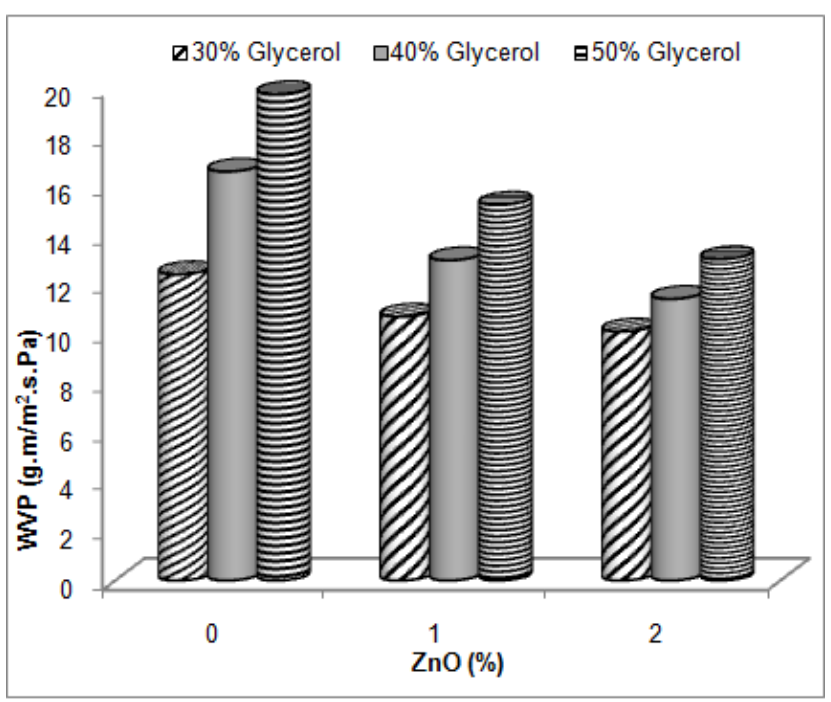

Figure 2. The Effect of Nano-ZnO on Glycerol in WVP
According to reference [17] added 30\% glycerol to a film, and its water vapor permeability increased from $41.61 \times 10$.

Figure 2 illustrates the effect of the nanoparticles on glycerol in WVP. The figure shows that as the percentage of nanoparticles is increased, the difference of the WVP between the levels of glycerol was reduced. For example, increase rate of the WVP in $0 \%$ nano- $\mathrm{ZnO}$, was 4.17 g.m $/ \mathrm{m}^{2}$.s.Pa (ranged $30 \%$ to $40 \%$ glycerol), and 3.14 g.m $/ \mathrm{m}^{2}$.s.Pa (ranged $40 \%$ to $50 \%$ glycerol), however these results for $2 \%$ nanoparticles, were 1.41 and 1.61 g.m $/ \mathrm{m}^{2}$.s.Pa, respectively. Thus, any increase in nanoparticles reduces the adverse effect of glycerol.

\subsection{Oxygen Permeability (OP)}

Figure 3 shows the oxygen permeability of the EVOH film. The figure shows that adding nanoparticles reduced the oxygen permeability. Also, adding glycerol to the film's matrix increases its oxygen permeability. However, as the percentage of nanoparticles increased, the oxygen permeability of the nanocomposite decreased.

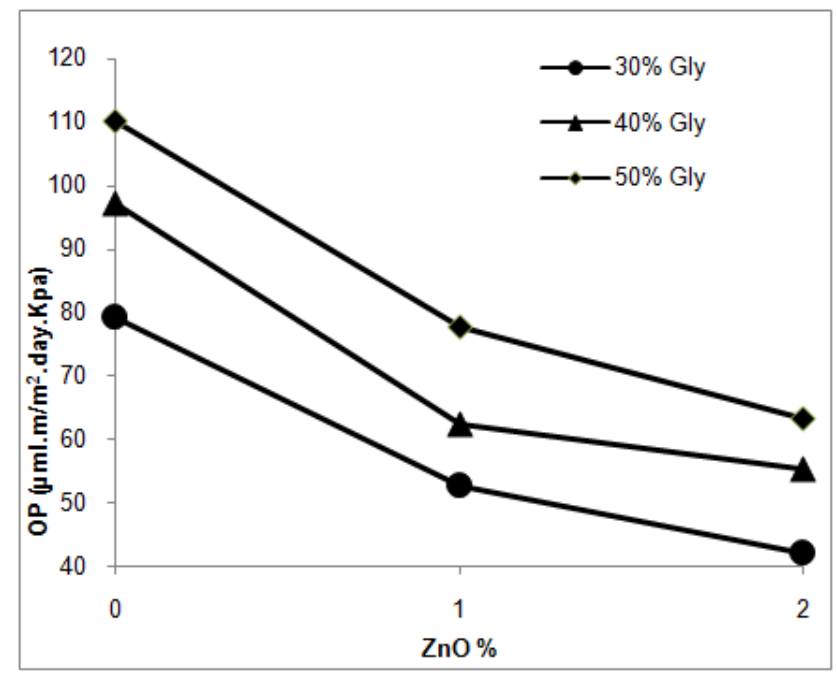

Figure 3. OP of the EVOH Film $($ Gly = Glycerol $)$

There are two reasons behind modifying the film with the addition of nanoparticles. First, smooth distribution of nanoparticles fills the pores in the film's matrix. Second, it creates a torturous path for oxygen to pass through by cross-linking between the nanoparticles and the film's matrix [14]. As reference [18] points out, adding nanoclay decreases oxygen permeability. Reference [19] found that cellulose nanocrystals decrease oxygen permeability in chitosan.

\subsection{Microscopy Characterization}

Figure 4 shows the SEM images. The SEM images were prepared in $1.00 \mu \mathrm{m}$ resolution.

According to the SEM images, the changes in the film's matrix were caused by the addition of glycerol. The EVOH polymer without glycerol is a homogenized polymer. Adding glycerol developed the path that the passing oxygen and water vapor must travel to pass through the EVOH film. Increasing the glycerol concentration amplified this phenomenon. According Fick's theory, glycerol influenced boundary layers, and subsequently, increases the diffusion coefficient [15]. 
Whereas, the addition of nanoparticles formed more tortuous paths in the matrix of the EVOH film. Thus, nanoparticles counteract the adverse effects of adding glycerol to EVOH films.

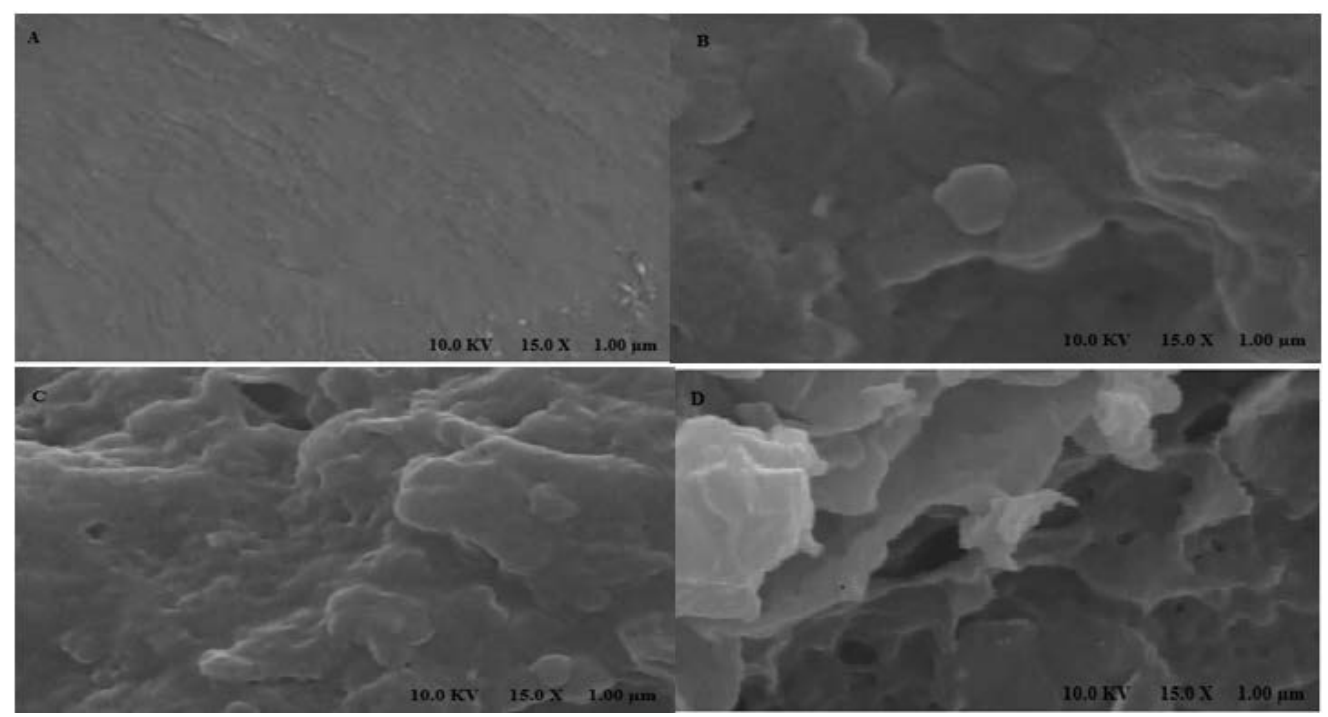

Figure 4. Images SEM (scale of $1.00 \mu \mathrm{m})$, A) EVOH film (without glycerol) B) EVOH film (30\% glycerol) C) EVOH film (40\% glycerol) D) EVOH film (50\% glycerol

\section{Conclusions}

In this study, EVOH film was prepared by solution mixing method. Nano-ZnO was added to the film's matrix to modify its properties. According to the results, adding nanoparticles, such Nano-ZnO improved barrier properties of the film's matrix. Although incorporating a plasticizer to prevent brittleness in the film was inevitable, it was found that nano- $\mathrm{ZnO}$ reduced the adverse effect of glycerol on the film's matrix. Nano-ZnO was major factor in diminishing the oxygen permeability and water vapor permeability of the film's matrix. By creating cross-linked structures and filling in the film's pores, nanoparticles improved the mechanical and barrier properties weakened by adding glycerol.

\section{Acknowledgement}

The author would like to thank Korakan Sarbotri for their contributions.

\section{References}

[1] Mokwena, K. K. - Tang, J. - Laborie, M.: Water absorption and oxygen barrier characteristics of ethylene vinyl alcohol films. Journal Food Engineering, 105(3), 2011, p.p 436-443.

[2] Gontard, N. - Guilbert, S. - Cuq, J.: Edible wheat gluten films: Influence of the main process variables on film properties using response surface methodology. Journal Food Science, 57(1), 1992, p.p 190-195.

[3] Yeo, J. H. - Hoon, L. C. - Park, C. - Lee, K.: Rheological, morphological, mechanical, and barrier properties of PP/EVOH blends. Advances Polymer and Technology, 20(3), 2001, p.p 191-201.

[4] Mokwena, K. K. - Tang, J.: Ethylene vinyl alcohol: A review of barrier properties for packaging shelf stable Foods. Critical Review Food Science, 52(7), 2012, p.p 640-650.

[5] Dastjerdi, R. - Montazer, M.: A review on the application of inorganic nano-structured materials in the modification of textiles: Focus on anti-microbial properties. Colloid Surface B, 79(1), 2010, p.p 5-18.
[6] Emamifar, A. - Kadivar, M. - Shahedi, M. - Soleimanianzad, S.: Evaluation of nanocomposite packaging containing $\mathrm{Ag}$ and $\mathrm{ZnO}$ on shelf life of fresh orange juice. Innovative Food Science \& Emerging Technologies, 11(4), 2010, p.p 742-748.

[7] Rhim, J. - Hong, S. - Park, H. - Ng, P. K. W.: Preparation and characterization of chitosan-based nanocomposite films with antimicrobial activity. Journal Agriculture Food Chemistry, 54(16) 2006, p.p 5814-5822.

[8] Fernandez-saiz, P. - Ocio, M. J. - Lagaron, M.: Antibacterial chitosan-based blends with ethylene vinyl alcohol copolymer. Carbohydrate Polymers, 80(3), 2010, p.p 874-884.

[9] ASTM D 882. Standard test method for tensile properties of thin plastic sheeting. West Conshohocken: ASTM International, 2001.

[10] ASTM E96. Standard test methods for water vapor transmission of materials. West Conshohocken: ASTM International, 1989.

[11] ASTM D1434. Standard test method for determining gas permeability characteristics of plastic film and sheeting. West Conshohocken: ASTM International, 1998.

[12] Kumar, P. - Sandeep, K. P. - Alavi, b. S. - Truong, V. D. - Gorga, R. D.: Preparation and characterization of bio-nanocomposite films based on soy protein isolate and montmorillonite using melt extrusion. Journal Food Engineering, 100(3), 2010, p.p 480-489.

[13] Cyras, V. P. - Manfredi, L. B. - Ton-That, M. - Vazquez, A.: Physical and mechanical properties of thermoplastic starch/montmorillonite nanocomposite films. Carbohydrate Polymers, 73(1), 2008, p.p 55-63.

[14] Cussler, E. L. - Highes, S. E. - Ward, W. J. - Aris, R.: Barrier membranes. Journal Membrane Science, 38, 1998, p.p 161-174.

[15] Lopez-de-Dicastillo, C. - Gallur, M. - Catala, R. - Gavara, R. Hernandez-Munoz, P.: Immobilization of b-cyclodextrin in ethylenevinyl alcohol copolymer for active food packaging applications. J Memberan Science, 353, 2010, p.p 184-191.

[16] Oguzlu, H. - Tihminlioglu, F.: Preparation and barrier properties of chitosan-layered silicate nanocomposite films. Macromolecular Symposia, 298(1), 2010, p.p 91-98.

[17] Kurek, M. - Scetar, A. - Voilley, A. - Galic, K. - Debeaufort, F.: Barrier properties of chitosan coated polyethylene. Journal Membrane Science, 403, 2012, p.p 162-168.

[18] Cerisuelo, J. P. - Alonso, J. - Aucejo, S. - Gavara, R. - HernandezMunoz, P.: Modifications induced by the addition of a nanoclay in the functional and active properties of an EVOH film containing carvacrol for food packaging. Journal Membrane Science, 423, 2012, p.p 247-256.

[19] Li, F. - Biagioni, P. - Finazzi, M. - Tavazzi, S. - Piergiovanni, L.: Tunable green oxygen barrier through layer-by-layer selfassembly of chitosan and cellulose nanocrystals. Carbohydrate Polymers, 92(2), 2013, p.p 2128-2134. 